\title{
Evaluation of the Permanent Deformations and Aging Conditions of Batu Pahat Soft Clay-Modified Asphalt Mixture by Using a Dynamic Creep Test
}

\author{
A. M. Al Allam ${ }^{1, a}$, M. I. M. Masirin ${ }^{1}$, M. E. Abdullah ${ }^{1}$ and A. S. Bader ${ }^{1}$ \\ ${ }^{1}$ Facultyof Civil and Environmental Engineering, Universiti Tun Hussein Onn Malaysia, 86400 Parit Raja, Johor, \\ Malaysia
}

\begin{abstract}
This study aimed to evaluate the permanent deformation and aging conditions of BatuPahat soft clay-modified asphalt mixture, also called BatuPahat soft clay (BPSC) particles; these particles are used in powder form as an additive to hot-mix asphalt mixture. In this experiment, five percentage compositions of BPSC $(0 \%, 2 \%, 4 \%, 6 \%$, and $8 \%)$ by weight of bitumen were used. A novel design was established to modify the hot-mix asphalt by using the Superpave method for each additive ratio. Several laboratory tests evaluating different properties, such as indirect tensile strength, resilient stiffness modulus, and dynamic creep, was conducted to assess the performance of the samples mixed through the Superpave method. In the resilient modulus test, fatigue and rutting resistance were reduced by the BPSC particles. The added BPSC particles increased the indirect tensile strength. Among the mixtures, 4\% BPSC particles yielded the highest performance. In the dynamic creep test, $4 \%$ BPSC particles added to the unaged and short-term aged specimens also showed the highest performance. Based on these results, our conclusion is that the BPSC particles can alleviate the permanent deformation (rutting) of roads.
\end{abstract}

\section{Introduction}

With the increase in the number of vehicles and the amount of load on road pavement, numerous casualties related to pavement deformation have occurred [1]. Truck tire pressure has also increased; as such, permanent deformation (rutting) has been considered as one of the most important types of asphalt pavement failure [2]. The rutting of asphalt pavements is also regarded as the main problem of flexible pavements [3]. In severe cases, permanent deformation gradually occurs through small distortions caused by repeated shear deformations under applied wheel loads; rutting or permanent deformation may be attributed to the plastic properties of an asphalt mixture under repeated loading; however, this phenomenon is unlikely related to the elastic properties of asphalt mixture [4]. Furthermore, rutting may be caused by mechanical deformation. Therefore, the mechanism by which permanent deformation occurs should be elucidated to enhance the performance of pavement design [5]. The asphalt binder aging of a hot-mix asphalt (HMA) mixture should also be understood to implement reasonable pavement designs and to apply these designs in construction [6]. Various

\footnotetext{
a Corresponding author : alallm84@yahoo.com
} 
additives for modified asphalt mixtures have been used to change the formation stage and to improve the engineering properties of asphalt mixtures [7].

Oxidative aging is the reaction of oxygen with an asphalt binder; the rate of this reaction depends on the characteristics of the asphalt binder and temperature [8]. Moreover, oxidation and volatilization cause asphalt pavements to retreat by increasing the stiffness of the binder, by enhancing the sensitivity to cracking, and by adversely affecting the structural performance of pavements [9]. As such, aging HMA pavements are evaluated to facilitate the prediction of the remaining fatigue on the aged HMA surfaces [10]. Furthermore, the manner by which asphalt undergoes aging differs on the basis of various aging processes; for instance, various asphalt types may age differently in the same environment. The severity of aging among different asphalts can also evaluated using different parameters [11]. For example, unmodified binders in pavements commonly harden and oxidize to a grade that exceeds the generally acceptable specifications of pavement aging [12]. Binder aging also influences the mechanical behavior of asphalt. Therefore, the stiffness of the aged binder increases as aging temperature increases [13]. Moreover, the effect of long-term aging on the pavement depends largely on the properties of the materials constituting the asphalt mixture [14]. Therefore, pavement aging should be investigated to help enhance the design of durable flexible pavements on the basis of mechanistic-empirical principles [6].

HMA mixtures are viscous materials generally used in pavement construction. Therefore, the techniques necessary to develop HMA on the basis of complicated behaviors should be understood to enhance the mechanical properties of the asphalt [15]. [16] used an additive called Nanoclay to improve the mechanical properties of the HMA; the performance of the Nanoclay-modified HMA is more efficient than that of the unmodified bitumen under dynamic creep. Clay nanoparticles are common materials used in asphalt construction. For instance, Nanoclay is used as an additive to reduce the degree of the permanent deformation and fatigue of asphalt mixtures [17]. Similar to Nanoclay, bentonite is used as an additive in a HMA mixture to enhance the mechanical properties of the asphalt mixture [18]. Likewise, hydrated lime can be added to HMA to improve the behaviors of resilient modulus and dynamic modulus [19]. Furthermore, kaolinite clay combined with polymermodified bitumen has been investigated to enhance storage stability; the use of the expanded clay in bitumen also improves the layers of wearing, as indicated by the volume of the mixture determined via a novel calculation method [20]. Recycled brick powder can also be used as an additive to asphalt mixture to enhance the mechanical performance of the asphalt mixture; the mixture modified with the recycled brick powder is more efficient than the mixture modified with limestone as a filler [21].

\section{Experimental Testing Method}

\subsection{Asphalt binder}

Malaysia experiences a tropical climate with high temperature and high humidity all throughout the year. As such, the production of performance-grade asphalt binder in this country depends on high temperature. The current study did not include low-temperature environments, because the temperature in this country hardly reach above $30{ }^{\circ} \mathrm{C}$ during daytime and the temperature rarely reach below $20^{\circ} \mathrm{C}$ during nighttime. Dense-grade asphalt mixtures were prepared using 80/100 penetrationgrade bitumen; the specific gravity of the asphalt binder is 1.03 .

\subsection{Batu Pahat soft clay (BPSC) particles as an additive}

BPSC particles were used as an additive to a HMA mixture; bitumen was modified with various ratios of BPSC $(0 \%, 2 \%, 4 \%, 6 \%$, and $8 \%)$ by weight of bitumen. Bitumen was heated in a draft oven at 150 ${ }^{\circ} \mathrm{C}$ for $1 \mathrm{~h}$; afterward, bitumen was mixed with the corresponding percentages of the BPSC particles for $15 \mathrm{~min}$ at $150{ }^{\circ} \mathrm{C}$. The modified bitumen was prepared using a high shear mixer at $3000 \mathrm{rpm}$; the 
modified BPSC was prepared using aggregates through a wet process. Table 1 presents the properties of the BPSC particles used in this research.

Table 1. Properties of BatuPahat soft clay.

\begin{tabular}{|c|c|}
\hline Parameters & Results \\
\hline Bulk Density $\left(\mathrm{mg} / \mathrm{m}^{3}\right)$ & 1.36 \\
\hline Specific Gravity & 2.66 \\
\hline Plastic Limit (\%) & $29.70 \%$ \\
\hline Liquid Limit (\%) & $37.55 \%$ \\
\hline Plasticity Index (\%) & $7.85 \%$ \\
\hline Moisture Content (\%) & $29.35 \%$ \\
\hline
\end{tabular}

\subsection{Aggregate properties and structure}

The allocation of the particle sizes of Superpave aggregate was determined through a design aggregate process. The aggregate gradation curve is shown in Figure 1. The aggregate gradations in this study were selected on the basis of ASTM D 3515-96 (D-4). Table 3 explains the gradation of the Superpave aggregate mix design with specific gravity.

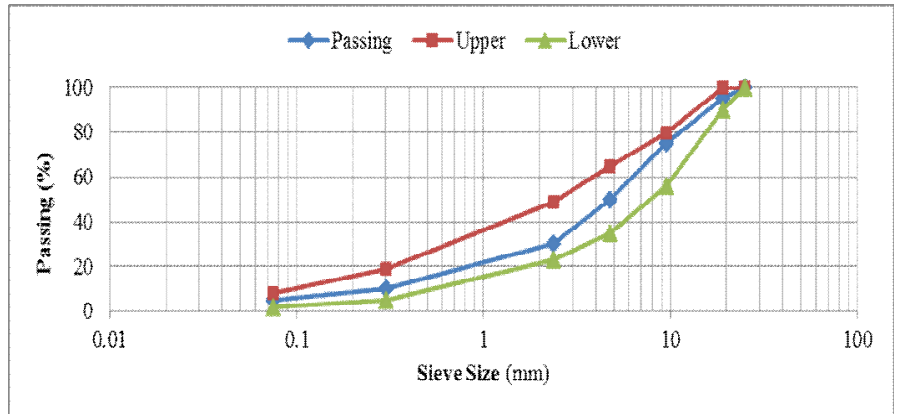

Figure. 1 Gradation curve of the aggregate mix design.

\subsection{Specimen preparation and compaction}

The HMA test specimens were prepared using a Superpave gyratory compactor. The Superpave samples were prepared in accordance with AASHTO T312 and PP-28-200. To enhance the Superpave HMA mixture, we mixed the components at optimum binder content with an acceptable volumetric property of $4 \%$ air voids on the basis of the Superpave standard of the design number of gyrations. The projected traffic load chosen in this study was $<30$ million ESALs, whereas a design number of gyrations $\left(N_{\mathrm{des}}\right)$ of 125 was selected. The compatibility of the asphalt mixture was assessed in terms of the initial number of gyrations $\left(N_{\text {ini }}\right)$ of nine gyrations and at the maximum number of gyrations $\left(N_{\max }\right)$ of 205 gyrations.

\subsection{Aging procedures}

The properties and performance of HMA can be accurately predicted by using aged test samples. All of the specimens were subjected to mixture conditioning. The mixture conditioning of the volumetric mixture design procedure was applied to laboratory-prepared loose mixtures only. The aggregate was placed in a forced-draft oven for $2 \mathrm{~h}$ to $4 \mathrm{~h}$ to equilibrate at the selected temperature. The asphalt binder was heated to $155^{\circ} \mathrm{C}$ for $2 \mathrm{~h}$. The mixture and the pan were placed in a forced-draft oven for 2 $\mathrm{h} \pm 5 \mathrm{~min}$ at $135^{\circ} \mathrm{C}$ for the unaged condition and at compaction temperature. The mixture was stirred 
after $60 \pm 5 \mathrm{~min}$ to preserve regular conditioning. The short-term aging procedure was designed to simulate the aging process during mixing and construction.

Table 2. Gradation of the aggregate superpave mix design with specific gravity.

\begin{tabular}{|c|c|c|c|}
\hline \multirow{2}{*}{ Sieve Size } & \multicolumn{3}{|c|}{ Percent Passing (\%) } \\
\cline { 2 - 4 } & Upper Limit & Lower Limit & Design \\
\hline $19 \mathrm{~mm}$ & 100 & 90 & 95 \\
\hline $9.5 \mathrm{~mm}$ & 80 & 56 & 75 \\
\hline $4.75 \mathrm{~mm}$ & 65 & 35 & 50 \\
\hline $2.36 \mathrm{~mm}$ & 49 & 23 & 30 \\
\hline $0.300 \mu \mathrm{m}$ & 19 & 5 & 10 \\
\hline $0.075 \mu \mathrm{m}$ & 8 & 2 & 5 \\
\hline
\end{tabular}

\section{Test methods}

\subsection{Resilient modulus test}

In contrast to the stiffness modulus, the resilient modulus has not been commonly used to represent the HMA stiffness because more emphasis has been placed on the dynamic modulus [22]. The resilient modulus test was conducted at 25 and $40{ }^{\circ} \mathrm{C}$. The resilient modulus at $25^{\circ} \mathrm{C}$ was based on the resistance of the mixture to fatigue; the resilient modulus at $40^{\circ} \mathrm{C}$ corresponds to the resistance of the mixture to rutting. These specifications were in accordance with the test standard procedure of ASTM D4123. In general, the stiffness modulus of asphalt mixtures is considerably reduced when temperature is increased. Strain was measured with a linear vertical differential transducer (LVDT); strain and applied stress were used to compute the resilient modulus of the design procedures. The specimens were kept in a universal testing machine (UTM) at $25 \pm 0.5^{\circ} \mathrm{C}$ for least $4 \mathrm{~h}$ before the test was performed. In the stiffness modulus tests, the samples were subjected to conditioning loading pulses. The applied force was automatically adjusted to determine the requested horizontal strain or deformation value [23].

\subsection{Dynamic creep test}

A dynamic creep test can be conducted by establishing repeated axial stress loading cycles and by measuring the resultant axial strain. In this study, the test was performed to assess the permanent deformation (rutting) potential of the asphalt mixtures; the test was also performed using the same specimens for the resilient modulus test. The concepts involved in the dynamic creep test are similar to those in the repeated shear test at a constant height. The test was also carried out using a UTM to apply the repeated axial stress pulses; vertical deformation was determined using LVDTs [24]. At high temperatures, an asphalt binder becomes less viscous. This decreased viscosity produces less stiff pavement that can be susceptible to creep caused by traffic loads. Hence, creep resistance is a mixture property desirable at high temperatures. In this study, the specimens with the a diameter of $100 \mathrm{~mm}$ and a loading stress of $100 \mathrm{kPa}$ were subjected to 3,600 loading cycles for approximately $1 \mathrm{~h}$. The test was conducted at $40^{\circ} \mathrm{C}$, and all of the samples were placed in a controlled temperature chamber for at least $1 \mathrm{~h}$ to reach a uniform mixture temperature [25].

\section{Results and Discussion}

\subsection{Resilient modulus test}

The resilient modulus test is a repeated indirect load tension test. The test method is described in ASTM D 4123. In the indirect tensile modulus test, a non-destructive process is applied to observe the effect of temperature and loading rate [23]. All of the samples were tested at 25 and $40{ }^{\circ} \mathrm{C}$. The 


\section{IConCEES 2015}

resilient modulus at $25{ }^{\circ} \mathrm{C}$ corresponds to the resistance of the mixture to fatigue; by contrast, the resilient modulus at $40{ }^{\circ} \mathrm{C}$ displays the resistance of the mixture to rutting. The loading pulse width and the pulse repetition period used in this study were set to 100 and $1000 \mathrm{~ms}$, respectively. The stiffness modulus of the asphalt mixtures is considerably reduced when the temperature was increased. The results of the resilient modulus tests are presented in Figures 2 and 3 for unaged and short-term aged specimens, respectively. For unaged specimens, the least susceptibility to fatigue deformation with the highest resilient modulus of $4944 \mathrm{MPa}$ was observed in 4\% BPSC particles, followed by $2 \%$ BPSC particles with the resilient modulus of $3993 \mathrm{MPa}, 6 \% \mathrm{BPSC}$ particles with the resilient modulus of $4895 \mathrm{MPa}$, and $8 \%$ BPSC particles with the resilient modulus of $4232 \mathrm{MPa}$; these particles were compared with the control sample with the resilient modulus of $4187 \mathrm{MPa}$. Similar trends were observed in the samples exposed to short-term aging.

As temperature increased to $40{ }^{\circ} \mathrm{C}$, the addition of $4 \%$ BPSC particles yielded a higher resilient modulus than the control sample (Figure 3). This finding indicated that $4 \%$ BPSC particles were less susceptible to rutting than the control mix with a resilient modulus of $762 \mathrm{MPa}$; likewise, $2 \% \mathrm{BPSC}$ particles were less susceptible to rutting than the control sample. Table 3 shows the aging index that represents the difference between unaged and aged samples at 25 and $40{ }^{\circ} \mathrm{C}$. To calculate the aging index, we divided the resilient modulus of the aged samples by the resilient modulus of the unaged samples. The results revealed that the short-term aged samples exhibited a higher stiffness modulus than the unaged specimens. Therefore, the highest value was determined at $4 \%$ BPSC particles during short-term aging. The aging indices (Table 3) showed that the susceptibility to oxidative aging was significantly reduced when the percentage by weight of the BPSC particles increased, especially in short-term aging.

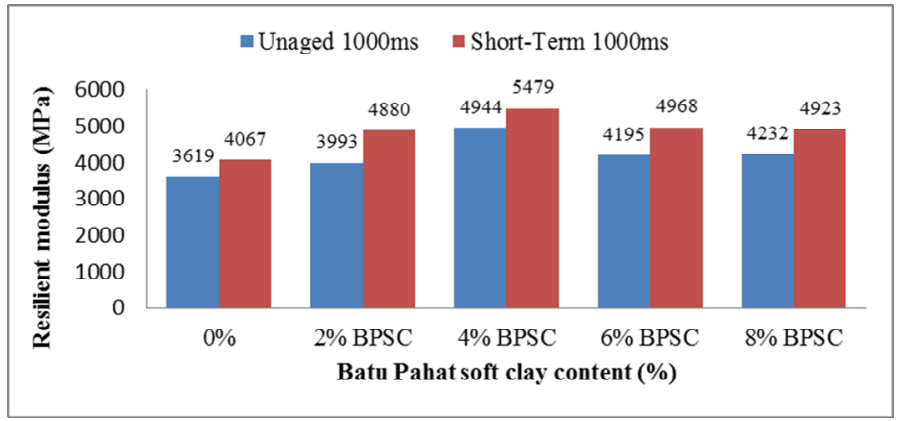

Figure 2. Resilient modulus test at $25^{\circ} \mathrm{C}$ (unaged and short-term aged specimens).

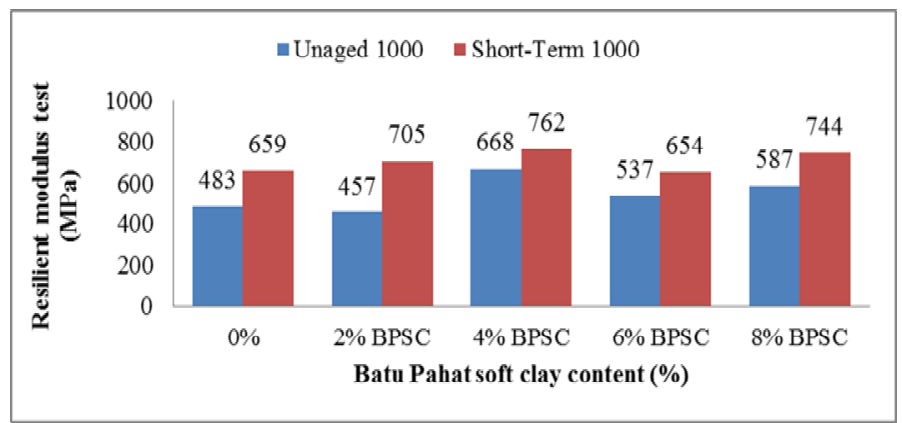

Figure 3. Resilient modulus test at $40{ }^{\circ} \mathrm{C}$ (unaged and short-term aged specimens). 


\section{MATEC Web of Conferences}

\subsection{Dynamic creep test}

Dynamic creep test is commonly used to determine the resistance of HMAs against permanent deformation [26]. This test is usually conducted by applying a static load to an asphalt mix sample, and the resultant rutting is observed through time. After the load is applied to the surface, the asphalt pavement deforms, despite the plurality of the deformation recapture after the load is extracted. This deformation is greatly affected by the number of cyclic loads and the environmental temperature. Thus, the dynamic creep test was conducted to describe the permanent deformation (rutting) performance of the control mixture and the BPSC-modified asphalt mixtures. During the loading cycles, a repetition time of $1000 \mathrm{~ms}$ (pulse periods of $100 \mathrm{~ms}$ with the rest periods of $900 \mathrm{~ms}$ ) was applied. Before the test was performed, all of the specimens were placed in a controlled temperature chamber for $3 \mathrm{~h}$ to reach the desired temperature of $40^{\circ} \mathrm{C}$. The dynamic creep test was conducted for 3,600 cycles.

Table 3. Aging indices for the resilient modulus test at 25 and $40{ }^{\circ} \mathrm{C}$.

\begin{tabular}{|c|c|c|c|}
\hline Samples & Temperature $\left({ }^{\circ} \mathbf{C}\right)$ & \multicolumn{2}{|c|}{ Aging Index } \\
\hline & & Unaged & Short-Term Aged \\
\hline Control & 25 & 1.00 & 1.12 \\
\hline $2 \%$ BPSC & 25 & 1.00 & 1.22 \\
\hline $4 \%$ BPSC & 25 & 1.00 & 1.10 \\
\hline $6 \%$ BPSC & 25 & 1.00 & 1.18 \\
\hline $8 \%$ BPSC & 25 & 1.00 & 1.16 \\
\hline Control & 40 & 1.00 & 1.36 \\
\hline $2 \%$ BPSC & 40 & 1.00 & 1.54 \\
\hline $4 \%$ BPSC & 40 & 1.00 & 1.14 \\
\hline $6 \%$ BPSC & 40 & 1.00 & 1.21 \\
\hline $8 \%$ BPSC & 40 & 1.00 & 1.26 \\
\hline
\end{tabular}

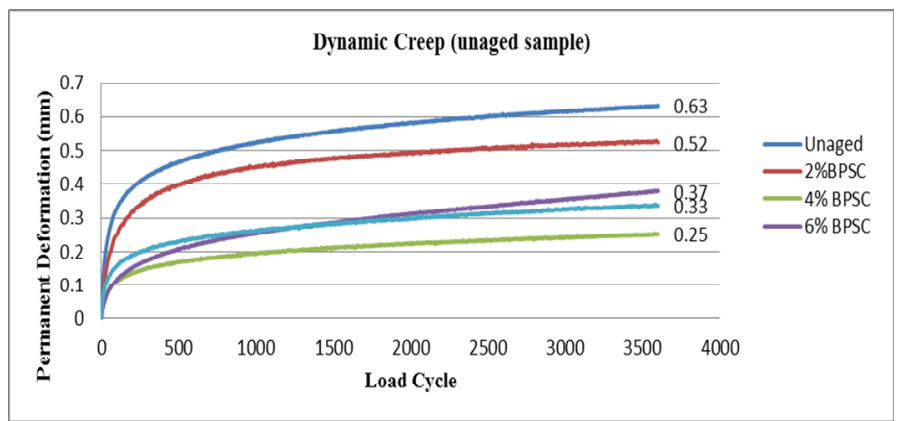

Figure 4. Dynamic creep test for the unaged specimens.

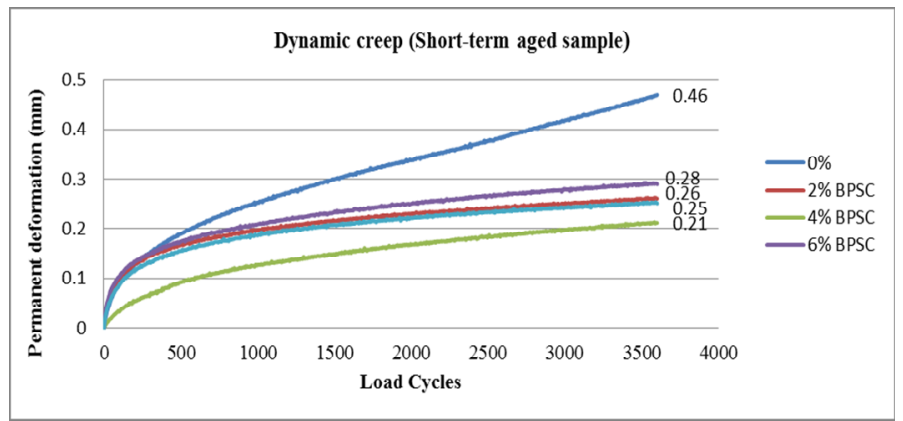

Figure 5. Dynamic creep test for the short-term aged specimens. 
In Figure 4, the lowest permanent deformation was observed at $0.25 \mathrm{~mm}$ and a load cycle of 3,600 in $4 \%$ unaged BPSC particles, followed by $2 \%, 6 \%$, and $8 \%$ of BPSC particles by weight and the control sample. Therefore, the BPSC particles improved the resistance to permanent deformation compared with the control mixes. Figure 5 also shows that 4\% short-term aged BPSC particles showed a lower permanent deformation value than the unaged specimens at $0.21 \mathrm{~mm}$ and a load cycle of 3600 . Hence, the lowest permanent deformation value was observed in $4 \%$ short-term aged BPSC particles, followed by $2 \%$ BPSC particles at $0.26 \mathrm{~mm}, 6 \%$ BPSC particles at $0.28 \mathrm{~mm}$, and $8 \%$ BPSC particles at $0.25 \mathrm{~mm}$ compared with the control mix at $0.46 \mathrm{~mm}$. Similar to the resilient modulus test, the dynamic creep test was conducted to calculate the aging index; in this procedure, the aged dynamic creep was divided by the unaged dynamic creep. The results showed that $4 \%$ BPSC exhibited the highest performance among the mixes. Thus, permanent deformation likely decreases after the shortterm aging occurred because aging conditions increased the stiffness of the asphalt mixtures. Table 4 shows the aging indices calculated through the dynamic creep test.

Table 4: Aging indices from the dynamic creep test at $40{ }^{\circ} \mathrm{C}$.

\begin{tabular}{|c|c|c|c|}
\hline \multirow{2}{*}{ Samples } & \multirow{2}{*}{ Temperature $\left({ }^{\circ} \mathbf{C}\right)$} & \multicolumn{2}{|c|}{ Aging Index } \\
\cline { 3 - 4 } & & Unaged & Short-Term Aged \\
\hline Control & 40 & 1.00 & 0.73 \\
\hline $2 \%$ BPSC & 40 & 1.00 & 0.50 \\
\hline $4 \%$ BPSC & 40 & 1.00 & 0.84 \\
\hline $6 \%$ BPSC & 40 & 1.00 & 0.76 \\
\hline $8 \%$ BPSC & 40 & 1.00 & 0.75 \\
\hline
\end{tabular}

\section{Conclusions}

On the basis of the limited laboratory work performed in this study, we concluded that 4\% BPSC particles were the optimal additive to enhance the performance characteristics of the HMA mixture. The moisture susceptibility of the mixes also improved, and the strength of the asphalt mixtures increased when the BPSC particles were added. Moreover, the resilient modulus of the mixtures prepared using the modified BPSC bitumen was higher than that of the control mixture. Stiffness significantly increased at $25{ }^{\circ} \mathrm{C}$ but decreased at $40{ }^{\circ} \mathrm{C}$. This research demonstrated that BPSC can decrease the susceptibility to permanent deformation (rutting) and can improve the resistance to fatigue in asphalt mixtures. The dynamic creep test was also performed at $40{ }^{\circ} \mathrm{C}$ and at different stress levels. The rutting properties of the BPSC-modified asphalt were evidently enhanced compared with those of the control mixture; among the mixtures, $4 \%$ BPSC showed the most efficient performance in terms of good resistance against permanent deformation.

\section{Acknowledgment}

The authors would like to acknowledge the contributions and the financial support by Office for Research, Innovation, Commercialization and Consultancy Management (ORICC) Found No (U033). The mixture testing work was completed in the University Tun Hussein Onn Malaysia.

\section{References}

[1] T.B. Moghaddam, M. Soltani and M.R. Karim, Experimental characterization of rutting performance of Polyethylene Terephthalate modified asphalt mixtures under static and dynamic loads, Constr. Build. Mater., 487-494, (2014).

[2] R. Garba, Permanent deformation properties of asphalt concrete mixtures, (2002).

[3] A. Golalipour, E. Jamshidi, Y. Niazi, Z. Afsharikia and M Khadem, Effect of aggregate gradation on rutting of asphalt pavements, Procedia-Social and Behavioral Sciences, 440-449, (2012). 
[4] G.P. He and W.G. Wong, Laboratory study on permanent deformation of foamed asphalt mix incorporating reclaimed asphalt pavement materials, Constr. Build. Mater., 8,1809-1819 (2007).

[5] B.A Feyissa, Analysis and modeling of rutting for long life asphalt concrete pavement, TU Darmstadt, (2009).

[6] P.E.Y. Wang, Y. Wen, K. Zhao, D. Chong and S.T.A. Wong, Evolution and locational variation of asphalt binder aging in long-life hot-mix asphalt pavements, Constr. Build. Mater., 68,172-182, (2014).

[7] H. Chen and Q. Xu, Experimental study of fibers in stabilizing and reinforcing asphalt binder, Fuel, 7, 1616-1622, (2010).

[8] J. Reed, Evaluation of the effects of aging on asphalt rubber pavements, Arizona State University, (2010).

[9] R. Lolly, Evaluation of short term aging effect of hot mix asphalt due to elevated, Arizona State University, (2013).

[10]H.P Bell, Fatigue evaluation criteria for aged hot-mix asphalt surfaces, Mississippi State University, (2009).

[11]C.T Chiu., Investigation of laboratory asphalt aging processes for development of an effective procedure to characterize asphalt durability, University of Florida, (1994).

[12] S.H Jung, The effects of asphalt binder oxidation on hot mix asphalt concrete mixture rheology and fatigue performance, Texas A\&M University, (2006).

[13] S. Saoula, K. Soudani, S. Haddadi, M. E. Munoz and A. Santamaria, Analysis of the rheological behavior of aging bitumen and predicting the risk of permanent deformation of asphalt, (2013).

[14]H.S Manual, American Association of state highway and Transportation Officials (AASHTO). Washington, (2010).

[15] Y. Xiao, Evaluation of engineering properties of hot mix asphalt concrete for the mechanisticempirical pavement design, (2009).

[16]S. Ro and S.R.T. Mi, Nanoclay-modified asphalt mixtures for eco-efficient construction. Nanotechnology in Eco-Efficient Construction: Materials, Processes and Applications, 108, (2013).

[17]J. Yang and S. Tighe, A Review of advances of nanotechnology in asphalt mixtures, ProcediaSocial and Behavioral Sciences, 1269-1276, (2013).

[18]H. Ziari, Evaluation of fatigue behavior of hot mix asphalt mixtures prepared by bentonite modified bitumen, Constr. Build. Mater., 685-691, (2014).

[19]I. Hafeez, M. A. Kamal, M. R Ahadi, and M. J Msawil, Effects of hydrated lime on fatigue and rutting behavior of HMA mixtures in dynamic modulus testing, Transportation Research, 1, 23, (2011).

[20]C. Ouyang, S. Wang, Y. Zhang and Y. Zhang, Preparation and properties of styrene-butadienestyrene copolymer/kaolinite clay compound and asphalt modified with the compound, Polymer Degradation and Stability, 2, 309-317, (2005).

[21] M. Z. Chen, J. T. Lin, S. P. Wu and C. H. Liu, Utilization of recycled brick powder as alternative filler in asphalt mixture, Constr. Build. Mater., 4,1532-1536, (2010).

[22]F. M. Nejad, A. R. Azarhoosh, G. H. Hamedi and M.J. Azarhoosh, Influence of using nonmaterial to reduce the moisture susceptibility of hot mix asphalt, Constr. Build. Mater., 384-388, (2012).

[23]T. Alataş and M. Yilmaz, Effects of different polymers on mechanical properties of bituminous binders and hot mixtures, Constr. Build. Mater., 161-167, (2013).

[24]A. Khodaii and A. Mehrara, Evaluation of permanent deformation of unmodified and SBS modified asphalt mixtures using dynamic creep test, Constr. Build. Mater, 7, 2586-2592 (2009).

[25]M. Dehnad, A. Khodaii and F.M. Nejad, Moisture sensitivity of asphalt mixtures under different load frequencies and temperatures, Constr. Build. Mater., 700-707, (2013).

[26]T. Alataş, M. Yılmaz, B. V. Kök and A. fatih Koral, Comparison of permanent deformation and fatigue resistance of hot mix asphalts prepared with the same performance grade binders, Constr. Build. Mater., 66-72, (2012). 